\title{
Circadian Rhythms Of Clock Gene Expression In The Cerebellum of Serotonin-Deficient Pet-1 Knockout Mice
}

\author{
Erin V. Paulus and Eric M. Mintz \\ Department of Biological Sciences and School of Biomedical Sciences, Kent State \\ University, Kent, $\mathrm{OH} 44242$
}

Corresponding Author:

Eric M. Mintz

College of Arts \& Sciences

Kent State University

Kent, $\mathrm{OH} 44242$

e-mail: emintz@kent.edu 


\section{Abstract}

Serotonin plays an important role in the central regulation of circadian clock function. Serotonin levels are generally higher in the brain during periods of high activity, and these periods are in turn heavily regulated by the circadian clock located in the suprachiasmatic nucleus. However, the role of serotonin as a regulator of circadian rhythms elsewhere in the brain has not been extensively examined. In this study, we examined circadian rhythms of clock gene expression in the cerebellum in mice lacking the Pet-1 transcription factor, which results in a developed brain that is deficient in serotonin neurons. If serotonin helps to synchronize rhythms in brain regions other than the suprachiasmatic nucleus, we would expect to see differences in clock gene expression in these serotonin deficient mice. We found minor differences in the expression of Per1 and Per2 in the knockout mice as compared to wild type, but these differences were small and of questionable functional importance. We also measured the response of cerebellar clocks to injections of the serotonin agonist 8-OH-DPAT during the early part of the night. No effect on clock genes was observed, though the immediate-early gene Fos showed increased expression in wild type mice but not the knockouts. These results suggest that serotonin is not an important mediator of circadian rhythms in the cerebellum in a way that parallels its regulation of the circadian clock in the suprachiasmatic nucleus.

\section{Keywords}

circadian; serotonin; cerebellum; period; clock; Fos 


\section{Introduction}

In mammals, the suprachiasmatic nucleus ( $\mathrm{SCN}$ ) within the ventral hypothalamus acts as an endogenous clock, generating circadian rhythms of physiology and behavior (Moore and Eichler, 1972; Stephan and Zucker, 1972). The neurotransmitter serotonin (5-HT) plays an important role in circadian rhythms, modulating photic input to the SCN as well as playing a role in non-photic shifts (Morin, 1999). Induced wheel-running increases 5-HT release in the SCN (Dudley et al., 1998) and causes phase advances along with associated downregulation of Per1 and Per2 expression (Maywood et al., 1999). ( \pm )-8-hydroxy-2-(dipropylamino)tetralin hydrobromide (8-OH-DPAT), a $5-\mathrm{HT}_{1 \mathrm{~A} / 7}$ receptor agonist, also causes phase advances during the subjective day (Cutrera et al., 1994; Cutrera et al., 1996; Edgar et al., 1993; Horikawa et al., 2000; Horikawa and Shibata, 2004; Mintz et al., 1997; Smith et al., 2008; Tominaga et al., 1992) that are associated with reductions in Per1 and Per2 expression (Horikawa et al., 2000). Taken together, these results suggest that Per1 and Per2 expression can be affected by $5-\mathrm{HT}$ signals that reset the clock.

In addition to the SCN, circadian oscillations of clock genes are also present in other areas within the brain and in peripheral tissues within the body (Abe et al., 2002; Damiola et al., 2000; Lamia et al., 2008; Tosini and Menaker, 1996; Yamazaki et al., 2000; Zylka et al., 1998). Studies both in vivo (Zylka et al., 1998) and in vitro (Abe et al., 2002; Yamazaki et al., 2000) have shown that rhythms generated in extra-SCN brain areas and peripheral tissues lag in phase behind the SCN, suggesting that signals from the SCN synchronize extra-SCN oscillators by a mechanism that is mostly yet unknown (Abe et al., 2002; Damiola et al., 2000; Pando et al., 2002; Yamazaki et al., 
2000). One brain site that expresses functional circadian clocks is the cerebellum. Per1, Per2, Clock, and Bmal1 are rhythmically expressed (Farnell et al., 2008; Rath et al., 2012) in the cerebellum, though one study did not find a rhythm in Clock (Shieh et al., 2005). Administration of tandospirone, a 5- $\mathrm{HT}_{1 \mathrm{~A}}$ receptor agonist, reduces Per1 expression in the cerebellum (Akiyama et al., 1999) suggesting that circadian clock function in the cerebellum is sensitive to serotonergic input. Serotonin concentrations in the cerebellum peak in the first half of the night in rats (Sanchez et al., 2008), consistent with the pattern seen in the SCN in hamsters (Dudley et al., 1998). The functional importance of circadian oscillations in the cerebellum is not known, however, there is some evidence that circadian function in the cerebellum contributes to the appearance of food-anticipatory activity during daily timed restricted feeding (Mendoza et al., 2010).

Pet-1 is an ETS domain transcription factor that is essential for the proper differentiation and development of serotonergic neurons. Mice lacking the Pet-1 gene show a significant disruption of the 5 -HTergic system with a $70 \%$ loss of 5 -HT cell bodies in adult animals (Hendricks et al., 2003). We have previously shown that serotonin-deficient Pet-1 knockout (KO) mice show a lengthening of period in constant darkness and redistribution of peak locomotor activity to the late portion of the night (Paulus and Mintz, 2012) suggesting that depletion of 5-HTergic input may lead to an endogenous clock with a longer free-running period. However, a separate study showed a similar redistribution of activity but a shortening of free-running period (Ciarleglio et al., 2014). Pet-1 KO mice also show alterations in response to photic stimuli, showing a smaller amplitude phase response curve to light that causes smaller phase delays (Paulus and Mintz, 2013). Since little is known about the signals that 
drive rhythms in extra-SCN neural clocks, Pet-1 mice provide a convenient model to investigate the potential role of 5-HT in synchronizing these rhythms. The cerebellum receives significant serotonergic input from the dorsal and median raphe (Hornung, 2003; Jacobs and Azmitia, 1992), structures with a significant influence on the central circadian clock in the SCN. Such inputs would provide an opportunity for information about arousal state to be communicated to cerebellar clocks. Therefore, we hypothesized that daily rhythms in serotonin release contribute to circadian rhythms of gene expression in the cerebellum. In this study we examine the temporal pattern of clock gene expression within the cerebellum, as well as the acute response of clock genes in the cerebellum to injections of the serotonin agonist 8-OH-DPAT.

\section{Results}

\subsection{Circadian Gene Expression in the Cerebellum}

Expression of the clock genes Per1, Per2, Clock, Bmal1, Npas2, and the immediateearly gene Fos across the 24-hour cycle was examined in the cerebellum of WT and Pet-1 KO animals. A summary of statistical findings is shown in Table 1, with the expression profile for each gene shown in Figure 1. Cerebellar Per1 expression showed rhythmic expression in both genotypes with peak expression occurring at ZT 16 in both WT and KO animals. An additional peak is seen at ZT 8 in WT but not in KO. There were also significant effects of genotype and an interaction indicating that the difference between genotypes at ZT 8 was statistically significant. Per2 expression also showed a rhythm in both genotypes with peak expression occurring at ZT 16 . There was a significant effect of genotype but no interaction indicating that there is significantly reduced Per2 expression overall in KO animals compared to WT, but that this reduction 
is not specific to particular times of day. Clock, Npas2, and Bmal1 expression also showed rhythmic expression in the cerebellum of both genotypes. Clock and Npas2 levels were highest during the day while Bmal1 levels were highest during the late night. Fos, however, is not rhythmically expressed in the cerebellum in either genotype. There were no significant effects of genotype and no interactions for Clock, Npas2, Bmal1, and Fos indicating that expression of these genes within the cerebellum is unaffected by deletion of the Pet-1 gene. Cerebellar expression of serotonin transporter (Sert) was also assayed. Expression levels were very low but there appeared to be no rhythm of Sert expression and no differences between genotypes, however, due to the low expression levels these data are not definitive (data not shown).

\subsection{Effects of 8-OH-DPAT on Cerebellar Clock Genes}

We next measured selected gene expression responses in the cerebellum to injection of 8-OH-DPAT (Figure 2). For Per1, there was no significant effect of 8-OH-DPAT administration $\left(F_{(1,19)}=3.67, p=0.07\right)$ or genotype $\left(F_{(1,19)}=1.54, p=0.23\right)$ and no interaction $\left(F_{(1,19)}=0.11, p=0.75\right)$. Similar to Per1, Per2 expression revealed no significant effect of 8-OH-DPAT administration $\left(F_{(1,19)}=0.09, p=0.76\right)$ or genotype $\left(F_{(1,19)}=0.02, p=0.89\right)$ and no interaction $\left(F_{(1,19)}=0.11, p=0.74\right)$. Fos expression showed no effect of treatment $\left(F_{(1,19)}=1.91, p=0.18\right)$ and no effect of genotype $\left(F_{(1,19)}\right.$ $=4.21, \mathrm{p}=0.054)$ but a significant interaction $\left(\mathrm{F}_{(1,19)}=5.73, \mathrm{p}=0.027\right)$ with 8-OH-DPAT administration causing increased Fos expression in WT animals $(197 \% \pm 32 \%$ of WT saline mean) but not in Pet- $1 \mathrm{KO}$ animals ( $83 \% \pm 16 \%$ of WT saline mean). Finally, we analyzed the expression of the $5-\mathrm{HT}_{7}$ receptor $(H t 7 r)$. There was no significant effect of 
8-OH-DPAT administration $\left(\mathrm{F}_{(1,19)}=0.81, \mathrm{p}=0.38\right)$ or genotype $\left(\mathrm{F}_{(1,19)}=0.31, \mathrm{p}=0.58\right)$ and no interaction $\left(F_{(1,19)}=0.06, p=0.81\right)$ in the cerebellum.

\section{Discussion}

The SCN is believed to coordinate rhythms of physiology and behavior (Ralph et al., 1990; Rusak and Zucker, 1979) and has been shown to have the ability to generate these rhythms in the absence of neural connectivity (Silver et al., 1996). Extra-SCN oscillators show rhythmic expression of clock genes (Abe et al., 2002; Damiola et al., 2000; Farnell et al., 2008; Lamia et al., 2008; Stokkan et al., 2001; Yamazaki et al., 2000; Zylka et al., 1998) which lag in phase behind the SCN and eventually dampen without SCN input (Abe et al., 2002; Damiola et al., 2000; Yamazaki et al., 2000) suggesting the SCN entrains rhythms in extra-SCN clocks via an unknown signal or signals. For extra-SCN clocks located in the brain, rhythms may be synchronized via direct neural input from the SCN, or by inputs from other brain regions that are secondary to behavioral rhythms driven by the SCN. For example, the SCN may drive rhythms of sleep and wakefulness, which in turn would drive serotonergic input to many brain regions. Pet-1 KO mice, therefore, provided a convenient model to examine 5-HT as a synchronizing factor in the cerebellum. Our results suggest that the clocks in the cerebellum are relatively insensitive to a loss of serotonergic input, but reveal new data on clock gene rhythms in the cerebellum.

Our experiment examining the temporal pattern of clock gene expression shows the expression of core clock genes within the cerebellum and provides support for the notion of the cerebellum as an extra-SCN oscillator. Our data confirms numerous studies showing that Per1 and Per2 are widely expressed outside the SCN including the 
cerebellum (Abe et al., 2002; Shieh, 2003; Sun et al., 1997). Additionally, Clock is also expressed widely throughout the brain (King et al., 1997) and within the cerebellum (Shieh, 2003), and Bmal1 expression has also been shown in the cerebellum (Farnell et al., 2008).

We show that Per1, Per2, Clock, Npas2, and Bmal1 all display rhythmic patterns of expression within the cerebellum of both WT and Pet-1 KO animals. Despite the fact that rhythmic expression of the immediate early gene, Fos, has previously been reported within the cerebellum (OHara et al., 1997), our experiments did not find Fos to be rhythmically expressed. However, the cerebellum is a heterogeneous structure, and our methodology produces an average of expression across the entire structure. If Fos is expressed rhythmically in some regions, it might not be detectable because such rhythmic expression is being averaged together with regions that lack rhythmic expression. Rhythmic expression of cerebellar Per1 and Per2 has been shown previously (Farnell et al., 2008; Sun et al., 1997). Our studies show peak levels of cerebellar Per1 and Per2 expression occurring at ZT 16 and lower levels of expression throughout the day in both genotypes. This pattern of expression is similar to those seen in other studies with the exception that previous reports show peak expression of Per genes around ZT 12 (Farnell et al., 2008; Sun et al., 1997). A separate study that examined the temporal pattern of clock gene expression in liver and skeletal muscle, sites of peripheral oscillators, found peak Per1 and Per2 expression at ZT 15, which is more similar to our results (Zylka et al., 1998). Although the cerebellum was not examined in Zylka et al. (1998), peak expression of Per1 and Per2 in cerebellum and liver has been shown to occur at the same time within the day (Farnell et al., 2008). 
Therefore, the discrepancy between our results and those of Sun et al. (1997) and Farnell et al. (2008) could be due to the differences in time points examined. Both previously published reports examined clock gene expression using samples collected at 6 hour intervals throughout the day while our samples were collected at 4 hour intervals. Since ZT 16 was not a time point examined in previous studies, it is possible that the time of maximal expression of Pergenes was missed in previous studies.

Our experiments show rhythmic expression of Bmal1 within the cerebellum of both genotypes, with peak expression occurring around ZT 20 in WT animals. Bmal1 has also previously been shown to be rhythmically expressed in the cerebellum with peak levels occurring at ZT 18 (Farnell et al., 2008). Again, the discrepancy between times of peak expression in the cerebellum between our experiments and those previously published could be due to differences in times of sample collection as ZT 20 was not a time point examined in the Farnell et al. (2008) study. Separate studies have shown Bmal1 expression peaks around ZT 20 - 22 in the liver (Lamia et al., 2008; McDearmon et al., 2006). Additionally, unlike the phase lag seen in expression of Per genes between the SCN and extra-SCN oscillators (Abe et al., 2002; Damiola et al., 2000; Yamazaki et al., 2000), peak expression of Bmal1 occurs at approximately the same time in SCN as well as extra-SCN clocks (Farnell et al., 2008) and peak Bmal1 expression within the SCN has been found anywhere between ZT 15 and ZT 22 (Shearman et al., 2000).

Our study found rhythmic cerebellar expression of Clock in both WT and KO animals. Clock has been shown to be constitutively expressed within the SCN (Shearman et al., 1999; Shearman et al., 2000). Several other studies have reported 
rhythmic expression of Clock in a variety of peripheral tissues suggesting that unlike in the SCN, Clock expression may be rhythmic in extra-SCN oscillators (Froy et al., 2009; Liu et al., 2007; Yamamoto et al., 2004).

Npas2 is similar to Clock in amino acid sequence (King et al., 1997) and the protein product, NPAS2, forms heterodimers with BMAL1 (Reick et al., 2001) and functionally interacts with BMAL1 in the SCN to regulate circadian rhythmicity in the absence of CLOCK (DeBruyne et al., 2007). We found that Npas2 was rhythmically expressed in the cerebellum of both genotypes with peak expression occurring at ZT 4 . Npas2 is rhythmically expressed in numerous peripheral tissues including the heart, lungs, liver, and kidneys with peak expression occurring early in the circadian day, from CT 0 to CT 5 (McNamara et al., 2001; Yamamoto et al., 2004). To our knowledge, this is the first study to examine the temporal pattern of Npas2 expression in the cerebellum.

Our results show rhythmic expression of Per1, Per2, Clock, Npas2, and Bmal1 in both WT and Pet-1 KO animals. These results suggest that $5-\mathrm{HT}$ does not function as a synchronizing signal for clock gene expression within the cerebellum. However, Per1 expression was significantly attenuated in the Pet-1 KO animals at ZT 8 as compared to WT. We are unsure of an explanation for this since no other studies examining Per1 expression in the cerebellum or peripheral tissues have reported similar findings. In addition, cerebellar Per2 expression, although rhythmic, is significantly attenuated in Pet-1 KO animals. This suggests that $5-\mathrm{HT}$ may play a role in modulation of the level of Per2 gene expression, however, the differences in expression of Per2, though statistically significant, was quite small and it is unclear whether such differences would have any biological relevance. We also note the appearance of a bimodal peak in WT 
expression of Per1 at ZT 8 and ZT 16. This might be a spurious finding, however, the difference between genotypes at ZT 8 is reflected by a similar (but not statistically significant) difference between genotypes in Per2 expression. Nevertheless, ZT 8 represents a time of day when $5-\mathrm{HT}$ release would normally be low due to inactivity of the animal, so it is difficult to ascribe a functional purpose for the observed pattern of expression.

In examining the effect of systemic 8-OH-DPAT injections at ZT 16, we found no differences between genotypes in expression of Ht7r, Per1, or Per2. However, Fos expression was significantly up regulated in WT animals two hours after 8-OH-DPAT administration when compared to $\mathrm{KO}$ animals. The consensus in the literature is that 5 $\mathrm{HT}_{1 \mathrm{~A}}$ receptors are not present within the cerebellum (Chalmers and Watson, 1991; Kia et al., 1996; Laporte et al., 1994; Pompeiano et al., 1992). 5-HT7 receptor expression, however, has been reported in the cerebellum (Geurts et al., 2002; Ruat et al., 1993). Our experiments confirm the presence of $H t 7 r$ expression within the cerebellum of both genotypes and provide evidence for a site of action for 8-OH-DPAT. However, we found no effect of 8-OH-DPAT administration on Per1 and Per2 expression in either genotype. We chose the ZT 16 time point because it is the time of day when serotonin release in the cerebellum would normally be high in WT but significantly attenuated in KO mice. Our results cannot distinguish between a cerebellar clock that is insensitive to 8-OH-DPAT vs. one that is insensitive at the particular time point we chose.

However, we can establish that the 8-OH-DPAT did have physiological effects on the cerebellum. Fos expression was significantly elevated in the cerebellum of WT but not $\mathrm{KO}$ animals two hours following a systemic injection of 8-OH-DPAT. Our results are 
similar to previously published results showing increased Fos mRNA in the cerebellum at 30 and 90 minutes following 8-OH-DPAT administration (Tilakaratne and Friedman, 1996). The lack of Fos induction in response to 8-OH-DPAT in KO animals may suggest a reduced capacity of $5-\mathrm{HT}$ receptors within the cerebellum to be activated by 5-HTergic compounds. However, induction of Fos mRNA peaks within $30-45$ minutes and rapidly declines, therefore, our study did not examine Fos expression at its peak time of induction. It would be of interest to investigate differences in Fos induction in response to 8-OH-DPAT along a shorter time course.

Our data suggests that developmental dysfunction of the $5-\mathrm{HT}$ system does not have a large influence on rhythmic expression of clock genes in the cerebellum, indicating that $5-\mathrm{HT}$ is not likely to be an important synchronizing factor for cerebellar clocks. It is possible that a greater change in clock function would be seen in a model with a total loss of serotonin neurons. However, small changes in Per1 expression and attenuated Per2 expression were seen in $\mathrm{KO}$ animals indicating that $5-\mathrm{HT}$ contributes somewhat to clock gene expression. No effect of 5-HT agonists was seen on core clock genes but there were significant reductions in Fos induction in $\mathrm{KO}$ animals, indicating that the developmental disruption of the serotonergic system may lead to reductions in the ability of 5-HT receptors to be activated by serotonergic agonists. Since we have already shown lengthening of free-running circadian period and shifts in timing of activity within the 24 hour cycle in Pet-1 KOs (Paulus and Mintz, 2012) as well as a reduced amplitude of the phase response curve to light leading to smaller phase delays (Paulus and Mintz, 2013), these data indicate that although serotonin plays an important 
role in regulating circadian rhythms in the SCN, it is not likely that it plays a similar role in circadian rhythms in the cerebellum.

\section{Experimental Procedure}

\subsection{Animals}

Pet-1 KO mice on a mixed 129Sv and C57BL/6 background were obtained from Dr. Evan Deneris (Case Western Reserve University, Cleveland, $\mathrm{OH}$ ) (Hendricks et al., 1999). Pet-1 heterozygote breeding pairs were used to produce all experimental animals. Experiments were conducted by matching siblings of different genotypes as much as possible to avoid bias from the mixed genetic background. At the time of weaning animals were ear-tagged and a tail-snip was collected for DNA extraction and genotyping. Experimental animals were entrained to a 12:12 light-dark (LD) cycle prior

to the start of the experiment, which occurred when the animals were aged 9-12 weeks. Food and water were available ad libitum and all experimental procedures were approved by the Kent State University Institutional Animal Care and Use Committee.

\subsection{Genotyping}

Tail snips from all animals were placed into an extraction buffer containing $20 \mathrm{mM}$ Tris $\mathrm{pH}$ 8.0, $1 \mathrm{mM}$ EDTA, $400 \mathrm{mM} \mathrm{NaCl}$, and $0.5 \%$ SDS with $20 \mathrm{mg} / \mathrm{mL}$ Proteinase $\mathrm{K}$ added in order to digest the snip. Samples were maintained at $55^{\circ} \mathrm{C}$ with slow rotation overnight. Supernatant from each sample was spun down in order to pellet DNA, rinsed with ethanol and resuspended in TE buffer. DNA of interest was amplified using PCR with primers from IDT (3' PET: 5' GCC TGA TGT TCA AGG AAG ACC TCG G 3' 5' 
PET: 3' CGC ACT TGG GGG GTC ATT ATC AC 3' 5' LOX: 5' CGG TGG ATG TGG AAT GTG TGC G 3') and thermocycler conditions beginning with a 3 minute hold at $94^{\circ} \mathrm{C}$ followed by 42 cycles of $94^{\circ} \mathrm{C}$ for 50 seconds, $62^{\circ} \mathrm{C}$ for 30 seconds and $72^{\circ} \mathrm{C}$ for 40 seconds. PCR product was analyzed using gel electrophoresis. Wild-type (WT) animals were identified by DNA fragments of 209 base pairs while Pet- 1 knockout (KO) animals were defined by DNA fragments of 361 base pairs.

\subsection{Gene expression time course experiment}

Adult male WT $(n=36)$ and KO $(n=30)$ were housed on a 12:12 light-dark (LD) schedule for at least two weeks prior to collection of samples. Animals were sacrificed by cervical dislocation at four hour intervals throughout the 24 hour day (ZT 0, ZT 4, ZT 8, ZT 12, ZT 16, and ZT 20). The experiment was conducted in a LD cycle, rather than in constant conditions, because the goal of the experiment was to measure the impact of serotonin on rhythms in the cerebellum under entrained conditions, not to evaluate changes in phase that might result in constant conditions. Brains were rapidly extracted, quickly frozen in isopentane that had been cooled on dry ice and stored at $80^{\circ} \mathrm{C}$ until ready for processing.

\subsection{8-OH-DPAT gene expression experiment}

Adult male WT $(n=12)$ and Pet-1 KO $(n=11)$ animals were housed on a 12:12 LD schedule for at least two weeks prior to the start of the experiment. At ZT 16, animals received either an injection of saline $(\mathrm{n}=11,6 \mathrm{WT}$ and $5 \mathrm{KO})$ or $8-\mathrm{OH}-\mathrm{DPAT}(5 \mathrm{mg} / \mathrm{kg})$ $(\mathrm{n}=12,6 \mathrm{WT}$ and $6 \mathrm{KO}$ ) intraperitoneally (i.p.). Two hours after drug or vehicle 
administration, animals were sacrificed by cervical dislocation, brains were rapidly extracted, frozen in isopentane that had been cooled on dry ice, and stored at $-80^{\circ} \mathrm{C}$ until ready for processing.

\subsection{Sample processing and analysis}

Brains were kept in a cooled chamber and the right half of the cerebellum was carefully dissected from the brain. Cerebellar tissue was homogenized using sonication and RNA was purified using a Qiagen RNeasy kit with an on-column DNase treatment (Qiagen) following the manufacturer's protocol. RNA quality and quantity from each sample was measured using a spectrophotometer and $1 \mu \mathrm{g}$ of total purified RNA was reverse transcribed to make cDNA using an Applied Biosystems TaqMan Reverse Transcription Reagents kit following the standard protocol and using random hexamers. qRT-PCR was performed on an Applied Biosystems Prism 7000 sequence detection system using TaqMan Universal Master Mix and Taqman primers (using the standard protocol) for Period genes (Per1 and Per2), Clock, Bmal1, Npas2, Ht7r, and the immediate early gene Fos, using gapdh as a control gene. All samples were assayed in triplicate with each triplicate containing $20 \mathrm{ng}$ of cDNA. Analysis of relative gene expression was performed using the $2^{-\Delta \Delta C T}$ method (Livak and Schmittgen, 2001). For ease of comparison, data was normalized by reporting levels of gene expression as a percentage of the WT mean value (experiment 1) or the WT saline mean (experiment 2) for each gene. Statistical analysis was performed using a two-way ANOVA with posthoc comparisons performed using a Tukey-Kramer test.

\section{Acknowledgements}


We would like to thank Evan Deneris for providing the Pet-1 knockout mice and Will Huffman for his technical assistance. Support for this project was provided by National Science Foundation grant IOS-1021957 and Kent State University. 
Table 1.

\begin{tabular}{ll|l|l}
\hline Gene & $\begin{array}{l}\text { Effect of } \\
\text { Genotype }\end{array}$ & Effect of Time & \multicolumn{2}{l}{ Interaction } \\
\hline Per1 & $\mathrm{F}_{(1,53)}=7.16$ & $\mathrm{~F}_{(5,53)}=41.65$ & $\mathrm{~F}_{(5,53)}=5.55$ \\
& $\mathbf{p}=\mathbf{0 . 0 0 9 9 ^ { * }}$ & $\mathbf{p}<\mathbf{0 . 0 0 0 1 ^ { * }}$ & $\mathbf{p}=\mathbf{0 . 0 0 0 4 ^ { * }}$ \\
\hline Per2 & $\mathrm{F}_{(1,53)}=5.36$ & $\mathrm{~F}_{(5,53)}=17.86$ & $\mathrm{~F}_{(5,53)}=0.74$ \\
& $\mathbf{p}=\mathbf{0 . 0 2 5 ^ { \star }}$ & $\mathbf{p}<\mathbf{0 . 0 0 0 1 ^ { * }}$ & $\mathrm{p}=0.60$ \\
\hline Clock & $\mathrm{F}_{(1,53)}=0.87$ & $\mathrm{~F}_{(5,53)}=2.66$ & $\mathrm{~F}_{(5,53)}=0.36$ \\
& $\mathrm{p}=0.36$ & $\mathbf{p}=\mathbf{0 . 0 3 2 ^ { * }}$ & $\mathrm{p}=0.87$ \\
\hline Npas2 & $\mathrm{F}_{(1,53)}=0.06$ & $\mathrm{~F}_{(5,53)}=12.36$ & $\mathrm{~F}_{(5,53)}=0.80$ \\
& $\mathrm{p}=0.81$ & $\mathbf{p}<\mathbf{0 . 0 0 0 1 ^ { * }}$ & $\mathrm{p}=0.56$ \\
\hline Bmal1 & $\mathrm{F}_{(1,53)}=0.04$ & $\mathrm{~F}_{(5,53)}=2.72$ & $\mathrm{~F}_{(5,53)}=1.05$ \\
& $\mathrm{p}=0.84$ & $\mathbf{p}=\mathbf{0 . 0 2 9 ^ { * }}$ & $\mathrm{p}=0.40$ \\
\hline Fos & $\mathrm{F}_{(1,53)}=1.23$ & $\mathrm{~F}_{(5,53)}=1.09$ & $\mathrm{~F}_{(5,53)}=1.42$ \\
& $\mathrm{p}=0.27$ & $\mathrm{p}=0.38$ & $\mathrm{p}=0.23$ \\
\hline
\end{tabular}

Table 1: Table summarizing the results of Per1, Per2, Clock, Npas2, Bmall, and Fos expression in the cerebellum of wild type and Pet-1 knockout animals at 4 hour intervals throughout the 24hour day. Statistically significant p-values are in bold text and denoted by asterisks. 


\section{Figure Legends}

Figure 1. Gene expression over the 24-hour day in the cerebellum of Pet-1 knockout mice (circles) and wild type mice (squares). The x-axis shows zeitgeber time (lights off at ZT12 and lights on at ZT 0). The y-axis shows expression relative to the wild type 24-hour mean value. *Significantly different from WT, $p<0.05$.

Figure 2. Relative gene expression for wild type (solid) and Pet-1 KO mice (hatched) after injection of 8-OH-DPAT or saline. *Significantly different from corresponding saline group, $p<0.05$. 


\section{Literature Cited}

Abe, M., Herzog, E.D., Yamazaki, S., Straume, M., Tei, H., Sakaki, Y., Menaker, M., Block, G.D., 2002. Circadian rhythms in isolated brain regions. Journal of Neuroscience. 22, 350-356.

Akiyama, M., Kirihara, T., Takahashi, S., Minami, Y., Yoshinobu, Y., Moriya, T., Shibata, S., 1999. Modulation of mPer1 gene expression by anxiolytic drugs in mouse cerebellum. British journal of pharmacology. 128, 1616-1622.

Chalmers, D.T., Watson, S.J., 1991. Comparative Anatomical Distribution of 5-Ht1a Receptor Messenger-Rna and 5-Ht1a Binding in Rat-Brain - a Combined Insitu Hybridization Invitro Receptor Autoradiographic Study. Brain Research. 561, 5160.

Ciarleglio, C.M., Resuehr, H.E.S., Axley, J.C., Deneris, E.S., McMahon, D.G., 2014. Pet-1 Deficiency Alters the Circadian Clock and Its Temporal Organization of Behavior. Plos One. 9.

Cutrera, R.A., Ouarour, A., Pevet, P., 1994. Effects of the 5-HT1a receptor agonist 8OH-DPAT and other non-photic stimuli on the circadian rhythm of wheel-running activity in hamsters under different constant conditions. Neuroscience letters. 172, 27-30.

Cutrera, R.A., Saboureau, M., Pevet, P., 1996. Phase-shifting effect of 8-OH-DPATa 5HT1A/5-HT7 receptor agonist, on locomotor activity in golden hamster in constant darkness. Neuroscience letters. 210, 1-4.

Damiola, F., Le Minh, N., Preitner, N., Kornmann, B., Fleury-Olela, F., Schibler, U., 2000. Restricted feeding uncouples circadian oscillators in peripheral tissues 
from the central pacemaker in the suprachiasmatic nucleus. Genes \& development. 14, 2950-1961.

DeBruyne, J.P., Weaver, D.R., Reppert, S.M., 2007. CLOCK and NPAS2 have overlapping roles in the suprachiasmatic circadian clock. Nature Neuroscience. $10,543-545$.

Dudley, T.E., Dinardo, L.A., Glass, J.D., 1998. Endogenous regulation of serotonin release in the hamster suprachiasmatic nucleus. Journal of Neuroscience. 18, $5045-5052$.

Edgar, D.M., Miller, J.D., Prosser, R.A., Dean, R.R., Dement, W.C., 1993. Serotonin and the mammalian circadian system: II. Phase-shifting rat behavioral rhythms with serotonergic agonists. Journal of Biological Rhythms. 8, 17-31.

Farnell, Y.Z., Allen, G.C., Nahm, S.S., Neuendorff, N., West, J.R., Chen, W.J.A., Earnest, D.J., 2008. Neonatal alcohol exposure differentially alters clock gene oscillations within the suprachiasmatic nucleus, cerebellum, and liver of adult rats. Alcoholism: Clinical and Experimental Research. 32, 544-552.

Froy, O., Chapnik, N., Miskin, R., 2009. Effect of intermittent fasting on circadian rhythms in mice depends on feeding time. Mechanisms of Ageing and Development. 130, 154-160.

Geurts, F.J., De Schutter, E., Timmermans, J.P., 2002. Localization of 5-HT2A, 5-HT3, 5-HT5A and 5-HT7 receptor-like immunoreactivity in the rat cerebellum. Journal of Chemical Neuroanatomy. 24, 65-74.

Hendricks, T., Francis, N., Fyodorov, D., Deneris, E.S., 1999. The ETS domain factor Pet-1 is an early and precise marker of central serotonin neurons and interacts 
with a conserved element in serotonergic genes. Journal of Neuroscience. 19, 10348-10356.

Hendricks, T.J., Fyodorov, D.V., Wegman, L.J., Lelutiu, N.B., Pehek, E.A., Yamamoto, B., Silver, J., Weeber, E.J., Sweatt, J.D., Deneris, E.S., 2003. Pet-1 ETS gene plays a critical role in 5-HT neuron development and is required for normal anxiety-like and aggressive behavior. Neuron. 37, 233-247.

Horikawa, K., Yokota, S., Fuji, K., Akiyama, M., Moriya, T., Okamura, H., Shibata, S., 2000. Nonphotic entrainment by $5-\mathrm{HT} 1 \mathrm{~A} / 7$ receptor agonists accompanied by reduced Per1 and Per2 mRNA levels in the suprachiasmatic nuclei. Journal of Neuroscience. 20, 5867-5873.

Horikawa, K., Shibata, S., 2004. Phase-resetting response to ( ) 8-OH-DPAT, a serotonin $1 \mathrm{~A} / 7$ receptor agonist, in the mouse in vivo. Neuroscience letters. 368, 130-134.

Hornung, J.P., 2003. The human raphe nuclei and the serotonergic system. J Chem Neuroanat. 26, 331-43.

Jacobs, B.L., Azmitia, E.C., 1992. Structure and function of the brain serotonin system. Physiol Rev. 72, 165-229.

Kia, H.K., Miquel, M.C., Brisorgueil, M.J., Daval, G., Riad, M., El Mestikawy, S., Hamon, M., VergÃ@, D., 1996. Immunocytochemical localization of serotonin1A receptors in the rat central nervous system. The Journal of comparative neurology. 365 , 289-305. 
King, D.P., Zhao, Y., Sangoram, A.M., Wilsbacher, L.D., Tanaka, M., Antoch, M.P., Steeves, T.D.L., Vitaterna, M.H., Kornhauser, J.M., Lowrey, P.L., 1997. Positional cloning of the mouse circadian clock gene. Cell. 89, 641-653.

Lamia, K.A., Storch, K.F., Weitz, C.J., 2008. Physiological significance of a peripheral tissue circadian clock. Proceedings of the National Academy of Sciences. 105, $15172-15177$

Laporte, A.M., Lima, L., Gozlan, H., Hamon, M., 1994. Selective in-Vivo Labeling of Brain 5-Ht1a-Receptors by [H-3] Way-100635 in the Mouse. European Journal of Pharmacology. 271, 505-514.

Liu, S., Cai, Y.N., Sothern, R.B., Guan, Y.Q., Chan, P., 2007. Chronobiological analysis of circadian patterns in transcription of seven key clock genes in six peripheral tissues in mice. Chronobiology International. 24, 793-820.

Livak, K.J., Schmittgen, T.D., 2001. Analysis of relative gene expression data using real-time quantitative PCR and the 2-[Delta][Delta] CT method. Methods. 25, 402-408.

Maywood, E.S., Mrosovsky, N., Field, M.D., Hastings, M.H., 1999. Rapid downregulation of mammalian period genes during behavioral resetting of the circadian clock. Proc Natl Acad Sci U S A. 96, 15211-6.

McDearmon, E.L., Patel, K.N., Ko, C.H., Walisser, J.A., Schook, A.C., Chong, J.L., Wilsbacher, L.D., Song, E.J., Hong, H.K., Bradfield, C.A., Takahashi, J.S., 2006. Dissecting the functions of the mammalian clock protein BMAL1 by tissuespecific rescue in mice. Science. 314, 1304-1308. 
McNamara, P., Seo, S.B., Rudic, R.D., Sehgal, A., Chakravarti, D., FitzGerald, G.A., 2001. Regulation of CLOCK and MOP4 by nuclear hormone receptors in the vasculature: A humoral mechanism to reset a peripheral clock. Cell. 105, 877 889.

Mendoza, J., Pevet, P., Felder-Schmittbuhl, M.P., Bailly, Y., Challet, E., 2010. The Cerebellum Harbors a Circadian Oscillator Involved in Food Anticipation. Journal of Neuroscience. 30, 1894-1904.

Mintz, E.M., Gillespie, C.F., Marvel, C.L., Huhman, K.L., Albers, H.E., 1997. Serotonergic regulation of circadian rhythms in Syrian hamsters. Neuroscience. 79, 563-569.

Moore, R.Y., Eichler, V.B., 1972. Loss of a circadian adrenal corticosterone rhythm following suprachiasmatic lesions in the rat. Brain research. 42, 201-206.

Morin, L.P., 1999. Serotonin and the regulation of mammalian circadian rhythmicity. Annals of Medicine. 31, 12-33.

OHara, B.F., Watson, F.L., Andretic, R., Wiler, S.W., Young, K.A., Bitting, L., Heller, H.C., Kilduff, T.S., 1997. Daily variation of CNS gene expression in nocturnal vs. diurnal rodents and in the developing rat brain. Molecular Brain Research. 48, 73-86.

Pando, M.P., Morse, D., Cermakian, N., Sassone-Corsi, P., 2002. Phenotypic rescue of a peripheral clock genetic defect via SCN hierarchical dominance. Cell. 110, 107117.

Paulus, E.V., Mintz, E.M., 2012. Developmental disruption of the serotonin system alters circadian rhythms. Physiol Behav. 105, 257-63. 
Paulus, E.V., Mintz, E.M., 2013. Photic and nonphotic responses of the circadian clock in serotonin-deficient Pet-1 knockout mice. Chronobiol Int.

Pompeiano, M., Palacios, J.M., Mengod, G., 1992. Distribution and Cellular-Localization of Messenger-Rna Coding for 5-Ht1a Receptor in the Rat-Brain - Correlation with Receptor-Binding. Journal of Neuroscience. 12, 440-453.

Ralph, M.R., Foster, R.G., Davis, F.C., Menaker, M., 1990. Transplanted suprachiasmatic nucleus determines circadian period. Science. 247, 975-978.

Rath, M.F., Rohde, K., Moller, M., 2012. Circadian Oscillations of Molecular Clock Components in the Cerebellar Cortex of the Rat. Chronobiology International. 29, 1289-1299.

Reick, M., Garcia, J.A., Dudley, C., McKnight, S.L., 2001. NPAS2: an analog of clock operative in the mammalian forebrain. Science. 293, 506-509.

Ruat, M., Traiffort, E., Leurs, R., Tardivellacombe, J., Diaz, J., Arrang, J.M., Schwartz, J.C., 1993. Molecular-Cloning, Characterization, and Localization of a HighAffinity Serotonin Receptor (5-Ht(7)) Activating Camp Formation. Proceedings of the National Academy of Sciences of the United States of America. 90, 85478551.

Rusak, B., Zucker, I., 1979. Neural regulation of circadian rhythms. Physiological Reviews. 59, 449-526.

Sanchez, S., Sanchez, C., Paredes, S.D., Cubero, J., Rodriguez, A.B., Barriga, C., 2008. Circadian variations of serotonin in plasma and different brain regions of rats. Molecular and Cellular Biochemistry. 317, 105-111. 
Shearman, L.P., Zylka, M.J., Reppert, S.M., Weaver, D.R., 1999. Expression of basic helix-loop-helix/PAS genes in the mouse suprachiasmatic nucleus. Neuroscience. 89, 387-397.

Shearman, L.P., Sriram, S., Weaver, D.R., Maywood, E.S., Chaves, I., 2000. Interacting molecular loops in the mammalian circadian clock. Science. 288, 1013-1019.

Shieh, K.R., 2003. Distribution of the rhythm-related genes rPERIOD1, rPERIOD2, and rCLOCK, in the rat brain. Neuroscience. 118, 831-843.

Shieh, K.R., Yang, S.C., Lu, X.Y., Akil, H., Watson, S.J., 2005. Diurnal rhythmic expression of the rhythm-related genes, rPeriod1, rPeriod2, and rClock, in the rat brain. Journal of Biomedical Science. 12, 209-217.

Silver, R., LeSauter, J., Tresco, P.A., Lehman, M.N., 1996. A diffusible coupling signal from the transplanted suprachiasmatic nucleus controlling circadian locomotor rhythms. Nature. 382, 810-813.

Smith, V.M., Sterniczuk, R., Phillips, C.I., Antle, M.C., 2008. Altered photic and nonphotic phase shifts in serotonin1A receptor knockout mice. Neuroscience. 157, 513-523.

Stephan, F.K., Zucker, I., 1972. Circadian rhythms in drinking behavior and locomotor activity of rats are eliminated by hypothalamic lesions. Proceedings of the National Academy of Sciences, USA. 69, 1583-1586.

Stokkan, K.A., Yamazaki, S., Tei, H., Sakaki, Y., Menaker, M., 2001. Entrainment of the circadian clock in the liver by feeding. Science. 291, 490-493. 
Sun, Z.S., Albrecht, U., Zhuchenko, O., Bailey, J., Eichele, G., Lee, C.C., 1997. RIGUI, a putative mammalian ortholog of the Drosophila period gene. Cell. 90, 10031011.

Tilakaratne, N., Friedman, E., 1996. Genomic responses to 5-HT1A or 5-HT2A/2C receptor activation is differentially regulated in four regions of rat brain. European Journal of Pharmacology. 307, 211-217.

Tominaga, K., Shibata, S., Ueki, S., Watanabe, S., 1992. Effects of 5-HT1A receptor agonists on the circadian rhythm of wheel-running activity in hamsters. European journal of pharmacology. $214,79-84$.

Tosini, G., Menaker, M., 1996. Circadian rhythms in cultured mammalian retina. Science. 272, 419-421.

Yamamoto, T., Nakahata, Y., Soma, H., Akashi, M., Mamine, T., Takumi, T., 2004. Transcriptional oscillation of canonical clock genes in mouse peripheral tissues. Bmc Molecular Biology. 5.

Yamazaki, S., Numano, R., Abe, M., Hida, A., Takahashi, R., Ueda, M., Block, G.D., Sakaki, Y., Menaker, M., Tei, H., 2000. Resetting central and peripheral circadian oscillators in transgenic rats. Science. $288,682-685$.

Zylka, M.J., Shearman, L.P., Weaver, D.R., Reppert, S.M., 1998. Three period homologs in mammals: differential light responses in the suprachiasmatic circadian clock and oscillating transcripts outside of brain. Neuron. 20, 1103-1110. 
Figures

Figure 1

\section{Per1}

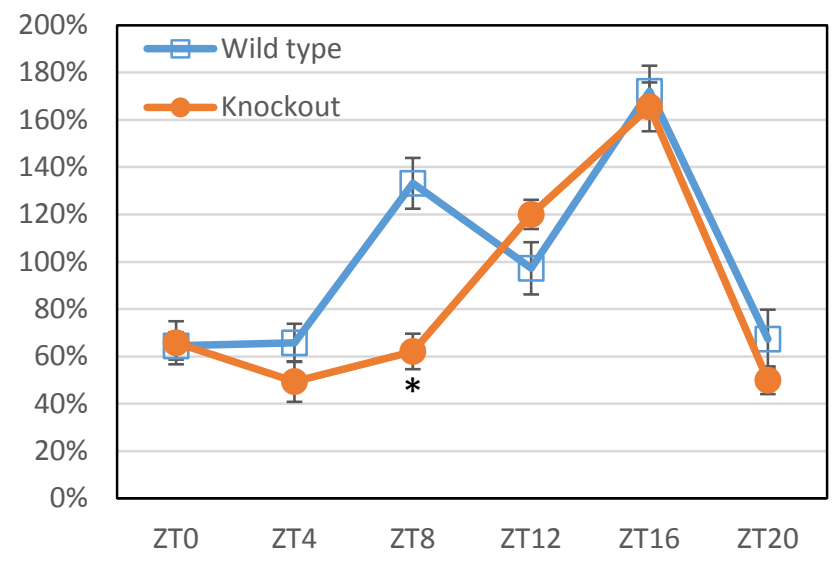

Clock

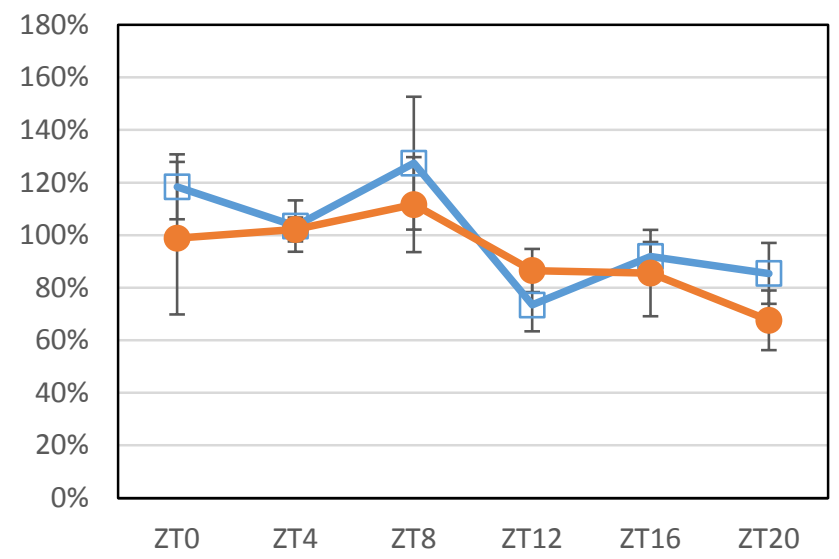

Bmal1

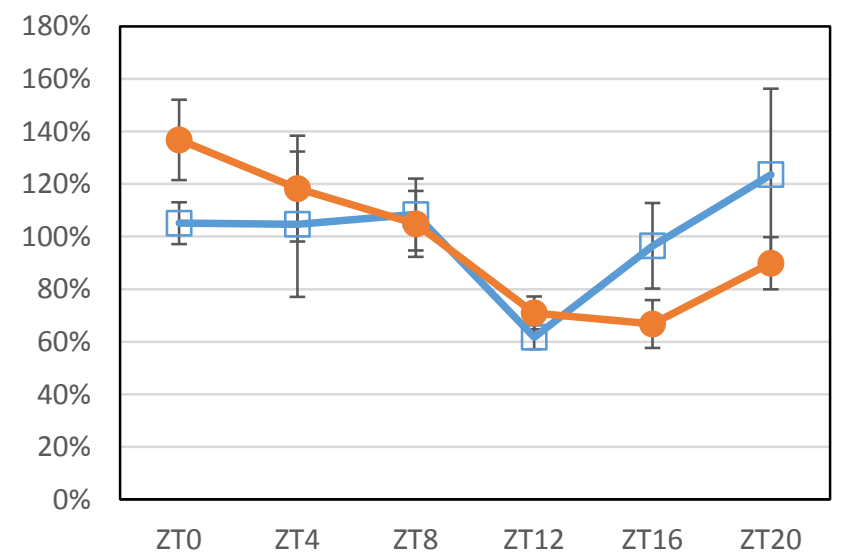

Per2

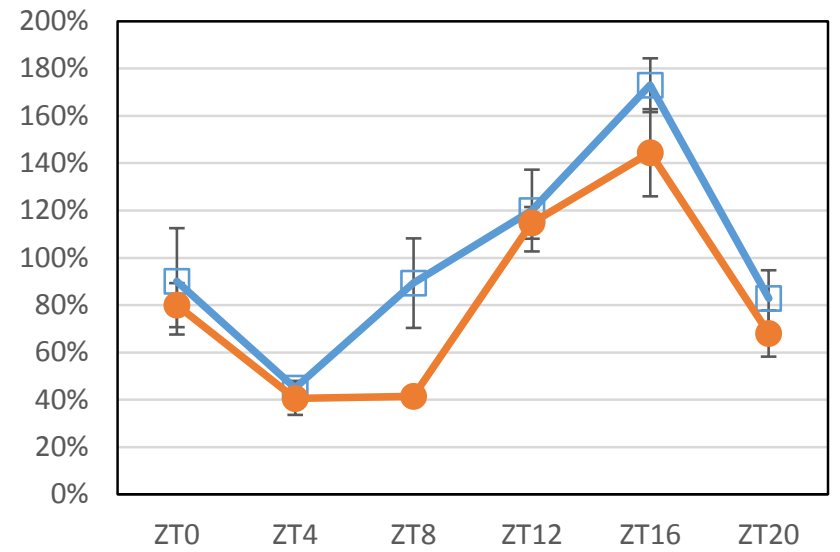

Npas2

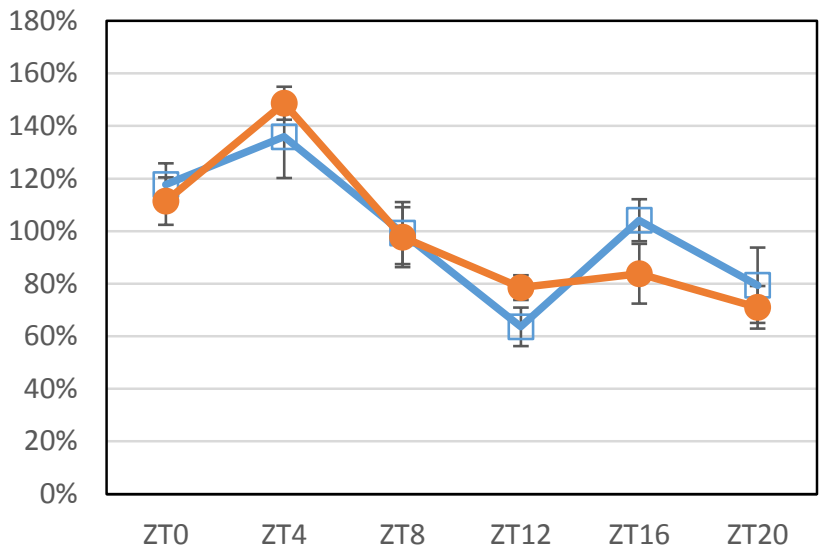

Fos

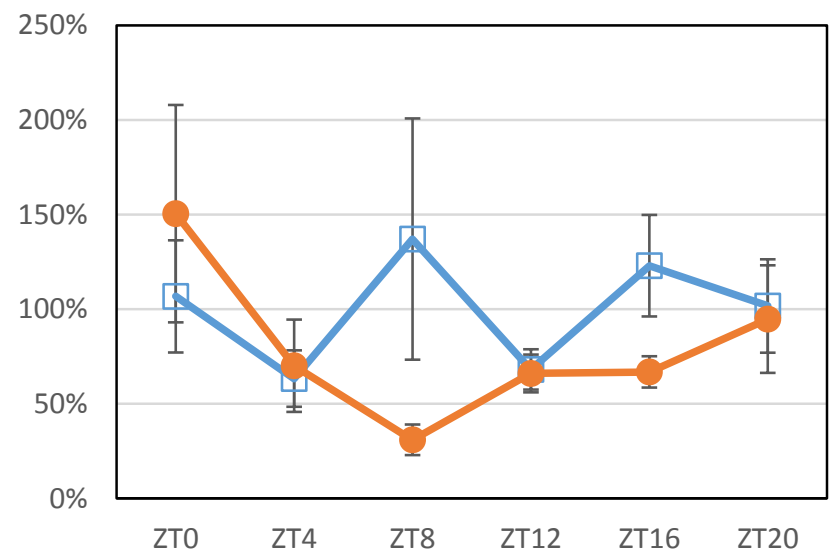


Figure 2

Per1

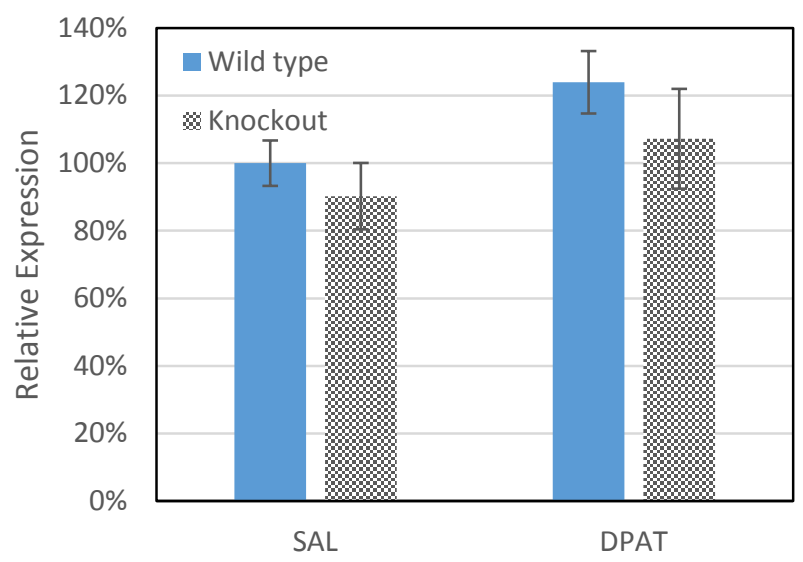

Fos

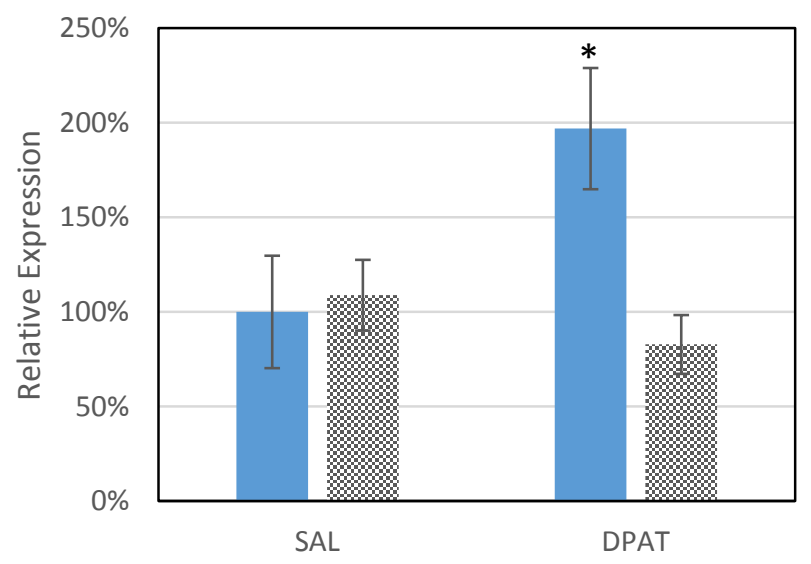

Per2

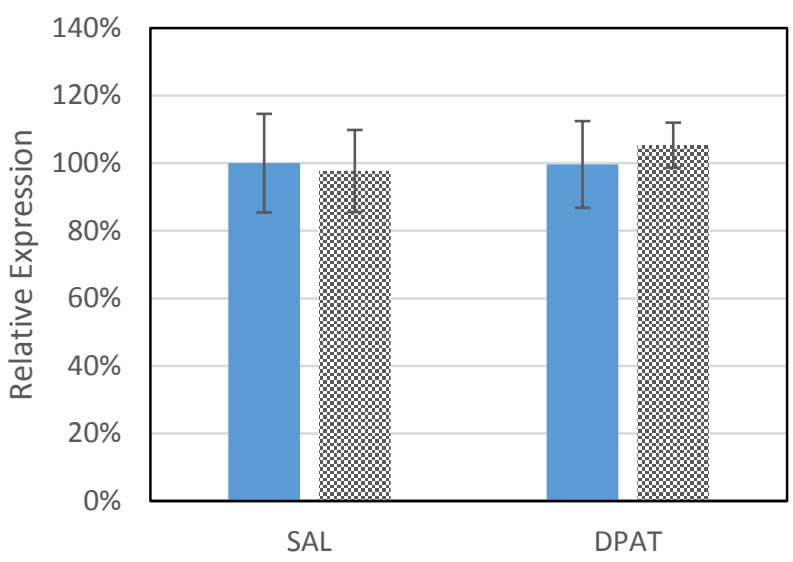

5ht7r

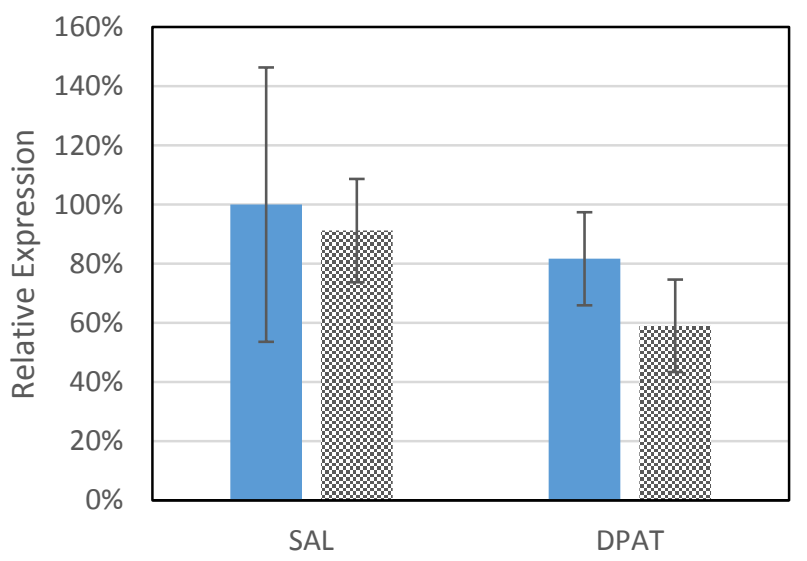

